\title{
Modified Northern blot protocol for easy detection of mRNAs in total RNA using radiolabeled probes
}

\author{
Tao Yang, Mingdi Zhang and Nianhui Zhang ${ }^{*}$ (])
}

\begin{abstract}
Background: Northern blotting is still used as a gold standard for validation of the data obtained from high-throughput whole transcriptome-based methods. However, its disadvantages of lower sensitivity, labor-intensive operation, and higher quality of RNA required limit its utilization in a routine molecular biology laboratory to monitor gene expression at RNA level. Therefore, it is necessary to optimize the traditional Northern protocol to make the technique more applicable for standard use.

Results: In this paper, we report modifications and tips used to improve the traditional Northern protocol for the detection of mRNAs in total RNA. To maximize the retention of specifically bound radiolabeled probes on the blot, posthybridization washes were performed under only with moderate-stringency until the level of radioactivity retained on the filter decreased to 20 50 counts per second, rather than normally under high and low stringency sequentially for scheduled time or under only high stringent condition. Successful detection of the low-expression gene using heterologous DNA probes in $20 \mu \mathrm{g}$ of total RNA after a two-day exposure suggested an improvement in detection sensitivity. Quantitatively controlled posthybridization washes combined with an ethidium bromideprestaining RNA procedure to directly visualize prestained RNA bands at any time during electrophoresis or immediately after electrophoresis, which made the progress of the Northern procedure to be monitored and evaluated step by step, thereby making the experiment reliable and controllable. We also report tips used in the modified Northern protocol, including the moderate concentration of formaldehyde in the gel, the accessory capillary setup, and the staining jar placed into an enamel square tray with a lid used for hybridization. Using our modified Northern protocol, eight rounds of rehybridization could be performed on a single blot. The modification made and tips used ensured the efficient proceeding of the experiment and the resulting good performance, but without using special reagents or equipment.

Conclusions: The modified Northern protocol improved detection sensitivity and made the experiment easy, less expensive, reliable, and controllable, and can be employed in a routine molecular biology laboratory to detect lowexpressed mRNAs with heterologous DNA probes in total RNA.
\end{abstract}

Keywords: Detection sensitivity, Formaldehyde-agarose gel, Northern blot analysis, Posthybridization wash

*Correspondence: zhangnianhui@scu.edu.cn

Key Laboratory of Bio-Resource and Eco-Environment of Ministry

of Education, College of Life Sciences, Sichuan University, Sichuan

610065 Chengdu, People's Republic of China

\section{Background}

The study of gene expression can provide us with knowledge about gene function and regulation. The multitiered technological methods used for identification of gene expression patterns can be divided into three categories: techniques for detecting the expression of one or a small 
number of genes, whole transcriptome-based approaches [1], and targeted next generation sequencing assays for the selected specific sets of genes or genomic regions [2]. Northern blot analysis, ribonuclease protection assay, and real-time polymerase chain reaction (qPCR) are the three most commonly used techniques for studying the expression of one or a small number of genes [1, 3, 4]. Among these three methods, qPCR is an often used technology in current molecular biology laboratories due to its extreme detection sensitivity, high specificity and throughput $[1,3,5,6]$. However, its prominent advantage of higher detection sensitivity also condemns the risk of the publication of inconsistent, irrelevant, and even misleading data based mostly on flawed qPCR results and associated interpretation because of the difference in the quality of RNA samples and the efficiency of reverse transcription (RT), and the inappropriate methodologies selected for the normalization and quantification of data $[7,8]$.

Compared to qPCR, the major limitations of Northern blot analysis are low detection sensitivity and easy RNA degradation by contaminated exogenous ribonucleases (RNases) in the course of extensive handling of RNA prior to blotting. Furthermore, Northern blotting is a relatively labor-intensive technique because the procedure consists of several steps $[1,3,4,9]$. Therefore, Northern blotting is not a desirable method for RNA analysis. However, it has the unique advantage of providing information about the expression level and size of the transcript so that it can be used to detect RNA degradation and alternative splice product of the same gene or repetitive sequence motifs, to reveal deletions or errors in transcript processing, and to isolate novel transcripts from heterogeneous mRNA pools $[1,3-5,9,10]$. In recent years, it has been aptly used to validate and study the size and relative abundance of small noncoding RNAs [11, 12]. Furthermore, because the signal strength obtained from Northern blotting is directly related to the gene copy number in the original sample, rather than being an extrapolated value influenced by the efficiency of RT or amplification as in RT-PCR, the true quantitation of the signal can be obtained by directly comparing changes in the RNA level between samples on a single membrane [9]. Therefore, Northern blotting is arguably a technique that provides highly valid gene expression data [13], and is often used as a gold standard for the validation of data obtained from high-throughput gene expression analysis $[9,13]$. In this context, it is necessary to optimize the traditional Northern protocol to make the technique more applicable for standard use.

The basic steps of Northern analysis have remained unchanged since the establishment of this method, but there are alternatives at every step because many variations and improvements have been made to the original protocol $[4,10]$, such as the modified Northern protocols for specific RNA detection, including the blue native Northern blotting for the detection of RNA in ribonucleoprotein complexes [14], the immuno-Northern blotting for the detection of modified RNA using gel separation and antibodies to modified nucleosides [15], and a recently reported modified Northern blotting, and a modified non-classical variation of Northern blotting, liquid hybridization assay, for sensitive mRNA detection [16]. But perhaps the most important advance in nucleic acid hybridization technology is the use of nonradioactively labeled probes, such as digoxigenin and biotin-based non-isotopically labeled probes [4, $10]$, and recently reported near infrared fluroscent dyelabeled probes [17]. Nonradioactive probes offer several advantages over radioactive probes, such as improved safety, higher stability, and lower cost $[4,10,11]$, but in practice, nonradioactive probes are not widely used in Northern blot analysis, which is most likely a reflection of their actually relatively low sensitivity and signal-tonoise ratio $[4,10,11]$. For an inexperienced investigator, a lot of efforts should be made to optimize the method so that it is reproducible for the particular task at hand. Therefore, this study modifies the Northern protocol using isotope-labeled probes due to the easily reproducible characteristics of the radioactive detection method. Our modifications made and tips used made it easy for the traditional Northern protocol to detect and quantify mRNAs: Posthybridization washes were performed only under moderately stringent conditions, and were quantitatively controlled to maximally retain the specific hybridized probes on the filter, thus improving detection sensitivity; in combination modified washes with a procedure of direct visualization of RNAs in the gel or blotted onto the membrane by ethidium bromide $(\mathrm{EtBr})$-prestaining RNA before electrophoresis [18], the progress of the whole Northern blotting procedure from the beginning of size-separation to the end of posthybridization detection could be monitored and evaluated step by step, thereby having a reliable and controllable experiment. The study also reported on the tips used to ensure the efficient proceeding of the experiment, including a moderate concentration of $12 \%$ formaldehyde in agarose gels to provide adequate capacity to maintain the denatured state of RNAs and, in the meantime, denaturing contaminated exogenous RNases, without compromising the subsequent blotting; measures taken to ensure efficient and successful blotting of size-separated RNAs onto the filter membrane by capillary transfer; a staining jar placed into an enamel square tray with a lid rather than special equipment used for hybridization to protect investigators from radioactivity, however, they 
still ensured the efficient hybridization of the fixed RNAs on the filter to probes. Using our modified Northern blot procedure, the filter could undergo up to eight rehybridizations cycles. Overall, our modified Northern protocol will not only improve the detection sensitivity, but will also make the experiment of Northern blotting easy, less expensive, reliable, and controllable.

\section{Results and discussion}

\section{Improved detection sensitivity by modification} of posthybridization washes: quantitatively controlled moderate-stringency washes

The principle of detecting specific mRNA in heterogenous mRNA pools by Northern blot analysis is based on the ability of the complementary single-stranded nucleic acid probe to form hybrid molecules with the target, in which after removal of the unbound and nonspecific bound probes, the specific bound probes on the membrane are detected by an appropriate detection technique $[4,10]$. Therefore, how to maximally retain the specific bound probes on the filter under the premise of the lower background by removing nonspecific bound probes at the step of posthybridization washes is one of the keys to improve detection sensitivity. However, according to traditional protocols, posthybridization washes are first performed under low stringent conditions to remove the hybridization solution and unhybridized probes, and then performed under high stringent conditions to remove partially hybridized nonspecific bound probes, and each round of washing is performed for at least 10 min $[4,9,10,19,20]$. Such prolonged washing can cause nonspecific and specific bound probes to be washdown from the membrane, which may be worse when detecting the expression of low expression genes. One of such examples is the detection of the expression of Aox 1, a gene expressed in low-copy number that encodes the mitochondrial alternative oxidase (AOX), which is a regulatory component embedded in the inner face of the mitochondrial inner membrane [21]. Successful detection of Aox 1 transcripts by Northern blot analysis can be achieved in two ways: using larger amounts of total RNA (30 $\mu$ g, e.g. [22]; or even up to $50 \mu \mathrm{g}$, e.g. [23]) or poly $(A)^{+}$RNA (e.g. [24-26]) for analysis, or still using total RNA even in $20 \mu \mathrm{g}$ of routine use, but changing the condition of posthybridization washes, such as washes only under high stringency, as in Borecký et al. [27]. It should be noted that all of the above examples use homologous probes for analysis. In the case of heterologous probes, due to the lower stability of the hybrids between the target and the mismatched probes, the radioactivity on the filter may be quickly washed down [20]. Figure 1a shows the failure to detect the expression of Aox 1 in vernalized germinating wheat using a probe of Aox 1 cDNA from tobacco [28] in strict accordance with the traditional posthybridization washing procedure [20], even the amount of RNA loaded for analysis was up to $50 \mu \mathrm{g}$ and the exposure time was extended to $5 \mathrm{~d}$, while detection of $18 \mathrm{~S}$ rRNA on the same filter gave a much stronger signal only after 30 min exposure. In wheat, there are two non-homologous genes (Waoxla and Waoxlc) encoding AOX, and both of them have low copy numbers [26]. The similarity of the nucleotide acid sequences between tobacco Aox 1 cDNA and the two wheat Aox 1 genes (Waoxla and Waox1c) was $74 \%$ and $71 \%$, respectively. Washes under only high stringency, as in Borecký et al. [27], also resulted in the quick washdown of the radioactivity from the filter (data not shown), which may be due to the quick stripping of heterologous probes by strong stringent washes [20]. Our modification was the tradeoff between procedures of the traditional protocol and under only high stringency of Borecký et al. [27], and only under moderate stringency in $1 \times \mathrm{SSC} / 0.1 \%$ SDS at 55 ${ }^{\circ} \mathrm{C}$, and the indication of the appropriate wash time was the radioactivity level monitored on the membrane until it decreased to $20 \sim 50 \mathrm{cps}$ by washing. Moderate-stringency washing can ensure that probes bound specifically are retained on the filter, and those bound nonspecifically are removed, thereby avoiding background signals. It was suggested that the filter membrane showing a Geiger counter reading of 10 20 counts per second (cps) was most suitable for subsequent developing [20]. Our standard was higher because the filter membrane retained higher radioactivity could be re-washed after seeing the results on the autoradiograph. However, once the filter membrane is excessively washed, it cannot be remedied, and the only way is to strip the probe and re-hybridize to the same probe.

Since specific probes were maximally retained on the filter, while background signals were avoided according to our modification, the low expression genes could be easily detected. Figure $1 \mathrm{~b}$ shows the successful detection of Aox 1 transcripts in $20 \mu \mathrm{g}$ of total RNA isolated from vernalized wheat by still using the tobacco Aox $1 \mathrm{cDNA}$ [28] as a probe (for full blots, see Suppl. Fig. 1). The signal could be detected after a two-day exposure, suggesting that our modification of posthybridization washes under only moderate stringency improves the detection sensitivity, which can be further verified by the successful detection of Aox1 transcripts in leaves at two-leaf stage of a chlorophyll-reduced oilseed rape and its wild type still using the same heterologous probe with the same Northern protocol (Fig. 1c) (for full blots, see Suppl. Fig. 2).

Except for the major advantages mentioned in the introduction, one minor advantage of Northern blot analysis is that sequences with only partial homology can be used as hybridization probes [9], which is important 


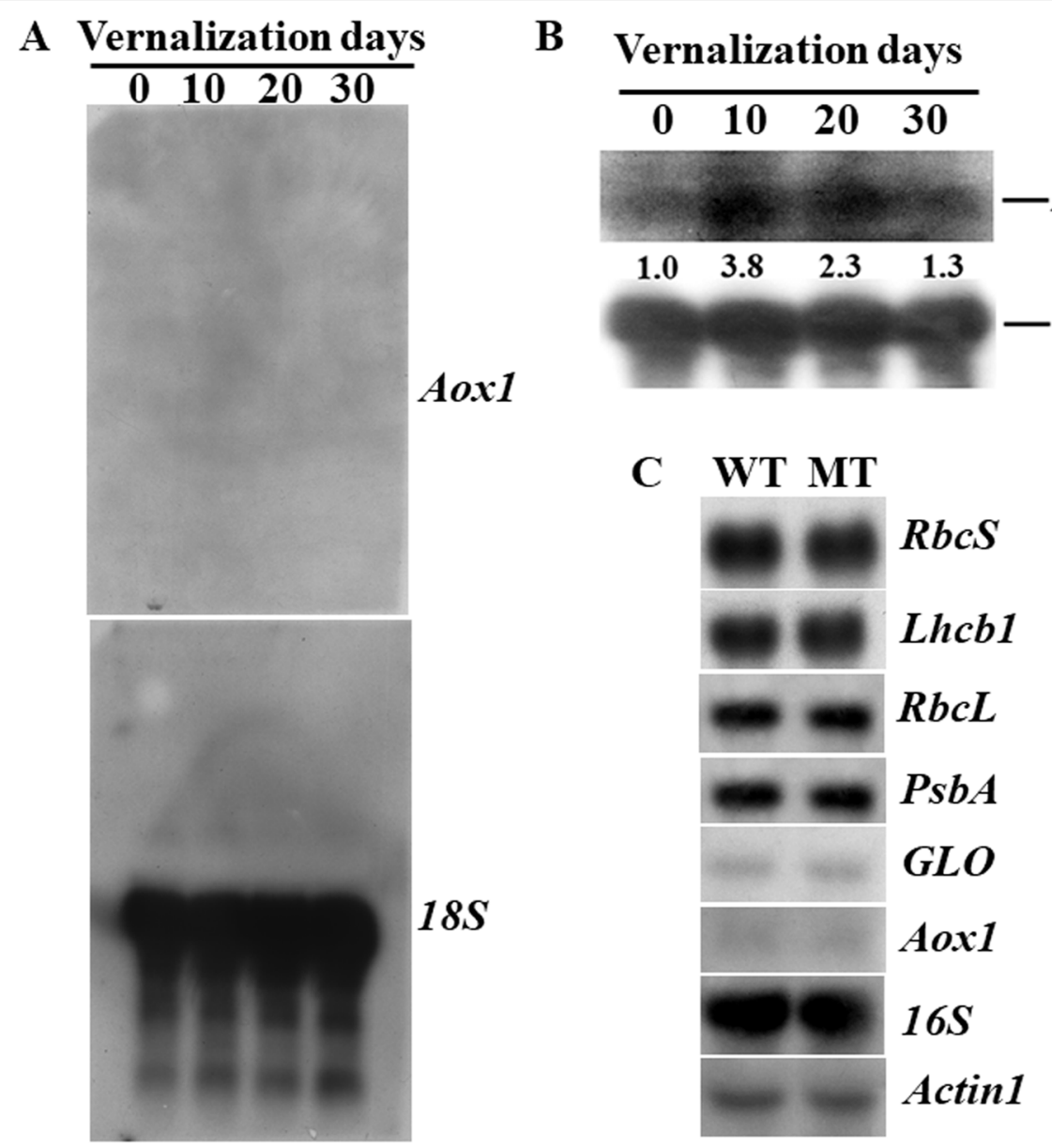

Fig. 1 Effects of the modified Northern protocol on the performance of Northern blot analysis. a Germinating wheat was vernalized at $0 \sim 2{ }^{\circ} \mathrm{C}$ for $0,10,20$, and $30 \mathrm{~d}$, respectively. The total RNA was isolated and an equal amount of total RNA (50 $\mu \mathrm{g})$ was resolved using the formaldehyde-agarose gel containing 12\% formaldehyde. Gel treatment, transfer of separated RNAs to a positively charged nylon membrane, fixation of transferred RNAs on the membrane, and prehybridization and hybridization were performed, as described in Methods. The traditional posthybridization washes under high and low stringency sequentially for scheduled time were performed according to Clark [20]. The probe used for detection was an Aox 1 CDNA from N. tabacum. Hybridization with $18 \mathrm{~S}$ was used as an internal control. The exposure times for the detecting Aox 1 and $18 \mathrm{~S}$ were $5 \mathrm{~d}$ and $30 \mathrm{~min}$, respectively. $\mathbf{b}$ An equal amount of total RNA $(20 \mu \mathrm{g})$ from vernalized germinating wheat at $0 \sim 2{ }^{\circ} \mathrm{C}$ for $0,10,20$, and $30 \mathrm{~d}$, respectively, was loaded to analyze the level of Aox 1 transcripts. Quantitatively controlled moderate-stringency washes were performed, as described in Materials and methods. The exposure times for the detection of Aox 1 and $18 \mathrm{~S}$ were $2 \mathrm{~d}$ and $30 \mathrm{~min}$, respectively. The values below the blot denote the fold-change relative to the germinating wheat without vernalization $(0 \mathrm{~d})$, standardized to the $18 \mathrm{~S}$ rRNA content. This experiment was performed twice with similar results. c An equal amount of total RNA $(20 \mu \mathrm{g})$ from the leaves of a chlorophyll reduced mutant of B. napus (MT) and its wild type (WT) grown in the field at two-leaf stage was subjected to RNA gel blot analysis following the modified protocol, as described in Materials and methods. Eight different probes were used to rehybridize to the same blot. The experiment performed twice, and the quantification of the hybridization signals from the autoradiographs showed that there was no significant difference in the expression of these genes investigated between the mutant and the wildtype oilseed rape

because homologous DNA or RNA probes are not always available. However, it can be seen from our results that partially matched heterologous DNA probes can be quickly stripped from DNA-RNA hybrids by high stringency posthybridization washes when the method is applied to monitor the expression of low-abundance mRNAs in total RNA. Consequently, the traditional Northern protocol should be modified for the particular task at hand. Our quantitatively controlled posthybridization washes under only moderate stringency improved detection sensitivity, thus allowing the method to be employed by using heterologous DNA probes to measure the steady state levels of minor mRNA species in total RNA. Therefore, this method is still feasible to detect the expression of low-abundance mRNAs when only heterologous DNA probes are at hand and/or the cell or 


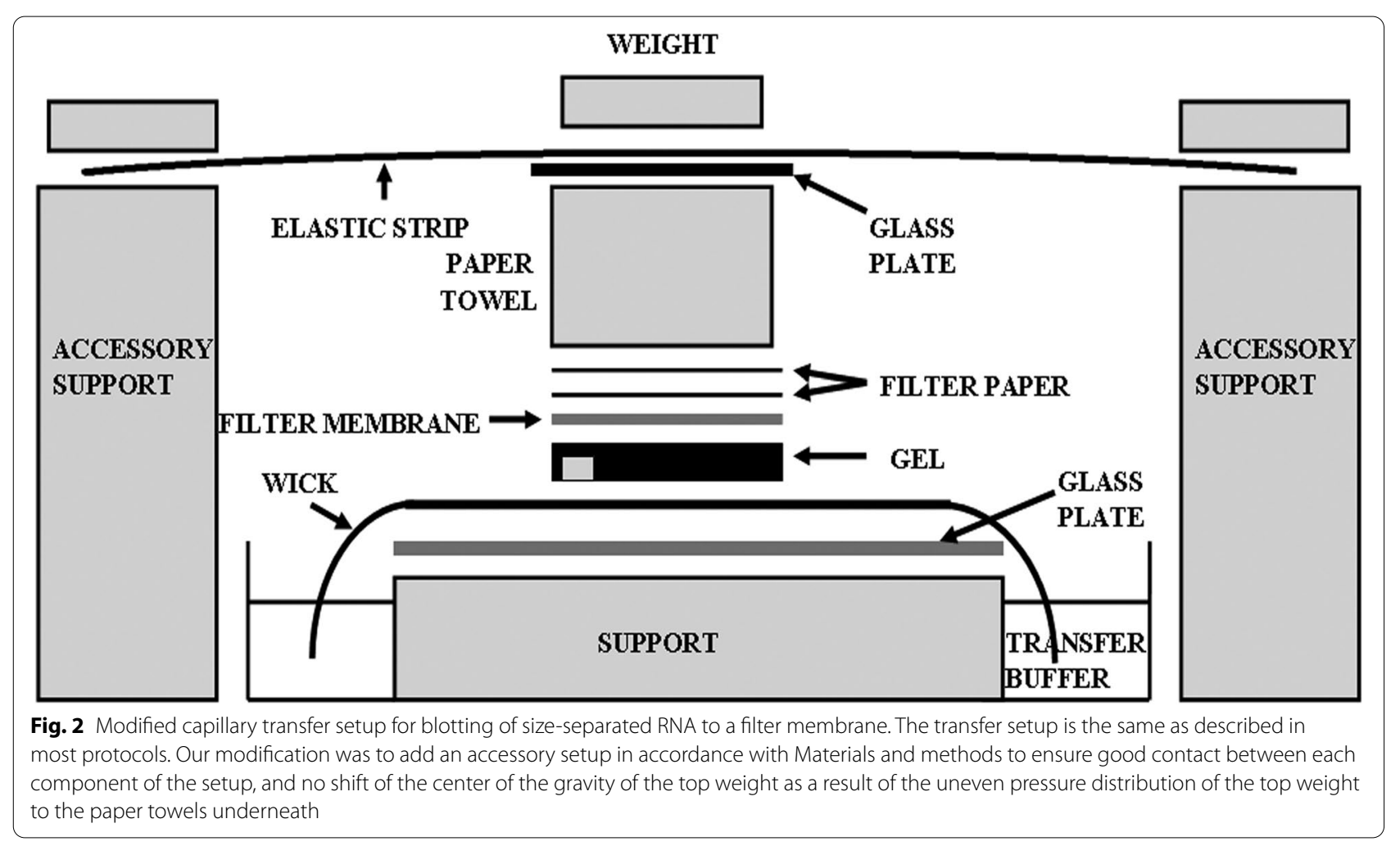

tissue source is limited because there is no need to isolate poly $(\mathrm{A})^{+}$mRNAs from a large amount of total RNA.

The disadvantage of our modified Northern protocol is the high background when detecting the expression of low-abundance mRNAs with heterologous DNA probes. This is because posthybridization washes is only performed under moderate stringency, and with a short time in order to avoid quick stripping of heterologous probes from the membrane. For example, our detection of Aox1 expression in vernalized wheat shoots and in a chlorophyll-reduced oilseed rape mutant at the two-leaf stage showed that the radioactivity on the membrane decreased to about 30 cps only after 11 and $12 \mathrm{~min}$ of washing, respectively (Suppl. Table 1). Furthermore, the probes were used directly after labelling for hybridization without purification to remove unincorporated $\left[\alpha-{ }^{32} \mathrm{P}\right]$ dCTP. As a result, unhybridized and nonspecific probes were not adequately stripped. However, the disadvantage of a high background was clearly outweighed by the advantage of obtaining the reproducible experimental results in a convenient and easy way when there was a limitation of the cell or tissue source for RNA gel blot analysis and only heterologous DNA probes were available. The high background in this situation can be lowered using purified labeled probes and/or using homologous probes and better antisense-RNA probes [4, 9] because of the higher stability of the hybrids and the greatest stability of RNA-RNA hybrids, thus the membrane can withstand longer time of posthybridization washes to strip off unhybridized and nonspecific probes.

\section{Monitoring the progress of Northern blotting: combination procedures of quantitatively controlled posthybridization washes with EtBr-prestaining RNA}

The Northern procedure is straightforward, thus it provides an opportunity to evaluate progress at various time points. For Northern analysis, the heart is the transfer of electrophoretically separated RNAs from the gel to a solid support for subsequent fixation and hybridization with specific probes. The quality of the size-separation of RNAs through formaldehyde-agarose gels can be evaluated by visualization of EtBr-stained RNA bands. However, the existence of formaldehyde in the gel can result in high background fluorescence if the gel is stained by conventional methods of incorporating $\mathrm{EtBr}$ into the entire gel or staining the gel after electrophoresis, which makes it impossible to visualize EtBr-stained RNA bands immediately after electrophoresis. An alternative staining procedure for prestaining RNA with a low concentration of $\mathrm{EtBr}(\leq 30 \mu \mathrm{g} / \mathrm{mL})$ prior to electrophoresis by heating RNA samples in the presence of $\mathrm{EtBr}$ before loading the gel makes it possible to directly visualize $\mathrm{EtBr}$-prestained RNA bands by ultraviolet (UV) light irradiation. Therefore, the verification of RNA integrity and evaluation of 
the quality of the size-separation can be performed at any time during electrophoresis or immediately after electrophoresis, and the transfer efficiency can also be checked immediately after blotting by viewing the membrane or gel directly on a UV transilluminator [18]. However, it has long been impossible to monitor the progress of posthybridization detection because posthybridization washes were performed for the scheduled time $[4,10$, 20 ] and the results can only be evaluated after viewing the results on the autoradiograph. However, in fact, the behavior of decreasing in the levels of radioactivity on the filter during washing can provide information on the efficiency of probe-labeling and hybridization, because the rapid decrease in radioactivity on the filter during washing may be due to poor labeling or insufficient hybridization [4, 20]. Therefore, our quantitatively controlled posthybridization washes enables posthybridization detection to be evaluated in advance during posthybridization washes, rather than after viewing the image on the autoradiograph like the conventional posthybridization washing procedure for the scheduled time. Overall, the combination of procedures of EtBr-prestaining RNA with quantitatively controlled posthybridization washes makes it possible to monitor and evaluate the progress of Northern blotting step by step, thereby making the experiment reliable and controllable.

\section{Efficient proceeding of Northern blot analysis with less expense: some tips}

The RNA samples subjected to Northern blot analysis are size-separated through an agarose-gel under denaturation conditions, and then the gel is treated by sequentially soaking in different solvents for its subsequent transfer $[4,10,19]$. Such extensive handling of RNA prior to blotting placed RNA in the danger of degradation by ubiquitous RNases, which are introduced accidently and subsequently resulted in the severely compromised outcome of Northern blotting. Therefore, an RNase-free environment should be created and maintained during these processes, especially when the isolated RNA samples are usually dissolved in a solvent such as DEPC- $\mathrm{H}_{2} \mathrm{O}$ without denaturants to inactivate RNases. In the process of RNA electrophoresis through formaldehyde-agarose gels, it is unnecessary to include special reagents in the system to maintain an RNase-free environment, because formaldehyde used for denaturing and maintaining the denatured state of RNA is also a denaturant of the RNase through the mechanism of formaldehyde reaction with amino and imino groups of amino acids to form Schiff bases [18]. For this reason, a higher concentration of formaldehyde was preferred to provide adequate denaturation to RNases and to compensate for the loss of formaldehyde through diffusion from the gel into the buffer during electrophoresis [4]. However, the existence of formaldehyde in agarose gels hinders subsequent blotting, thus a prolonged soaking in DEPC- $\mathrm{H}_{2} \mathrm{O}$ or other solvents is required to remove formaldehyde in the gel prior to setting up the transfer [10]. Therefore, the concentration of formaldehyde in the gel should be moderate, which is also a fairly variable parameter in different protocols, such as often used at $18 \%[4,19]$ or $16 \%$ [20], or much lower even at 5\% [10] or 3\% [9]. In our practice, agarose gels containing $12 \%$ formaldehyde were found to achieve the best combination of denaturation to both RNA and RNases during electrophoresis, without hindrance to subsequent blotting of size-separated RNAs to the solid support, simply by soaking the gel in DEPC- $\mathrm{H}_{2} \mathrm{O}$ for $10 \mathrm{~min}$.

Electrophoretically resolved RNA can be blotted onto a solid support using a commercially fast transfer apparatus, such as electroblotting and a vaccumblotting apparatus, but the traditional simple and no instrumentation-required capillary transfer can still work well [4, 10]. We used the simple and economical upward capillary transfer at neutral $\mathrm{pH}$, and the transfer setup was basically the same as that described in most protocols $[4,10,19,20]$. This simple method is quite reliable, but based on our experience, we found that the deformation of the wetted paper towels might result in inefficient transfer because the wetted paper towels would extend horizontally, and then would be deformed and creased. Therefore, the gel over the area of the crease may lead to the non-uniformity of capillary action. In addition, the wetted area of paper towels would shrink vertically. Due to the uneven wetting performance of the paper towels, the vertical shrinkage of paper towels was also uneven, resulting in uneven pressure distribution from the top weight to the paper towels underneath, which in turn causes deviations in the center of gravity of the top weight, and finally the collapse of the setup. To avoid these problems, the first measure was to flatten the first few layers of paper towels placed on the filter paper. However, even if so, the transfer setup easily collapsed during overnight transfer as soon as the pressure of the top weight was unevenly distributed to the paper towels underneath, especially when the gel was narrow if only two or three lanes were used and the unused area of the gel was trimmed away as recommended (e.g. [10]). Our major precaution was to add an accessory setup to both sides of the transfer setup (Fig. 2) to ensure good contact between the various components of the transfer setup, and ensure that the pressure of the top weight is evenly distributed to the paper towels underneath, thus the center of gravity of the top weight does not shift during transfer process. To avoid the diffusion of bands, the top weight should not be too heavy, as a $200 \mathrm{~g}$ of weight 
is sufficient; to ensure the complete transfer, the transfer time was up to $18 \mathrm{~h}$.

To prevent higher doses of radioactivity, the hybridization oven is the best choice for hybridization of Northern blots, whose thick glass tubes can efficiently shield radioactivity. We performed prehybridization in a staining jar (Fig. 3a). During hybridization, the staining jar was placed into an enamel square tray with a lid (Fig. 3b). After covering the lid, the enamel tray was taken into a laboratory incubator and stationary hybridization was allowed at $42{ }^{\circ} \mathrm{C}$ for $15 \mathrm{~h}$. The quadrate bottom of the staining jar made it possible to use small volumes of liquid, thus making the probe more concentrated. Radioactivity could be reduced by the thick glass of the staining jar, and shielded by the metallic material and the enamel of the enamel square tray. Our hybridization system can also prevent evaporation of toxic formamide and spillage of radioactivity. Compared to other recommended economical homemade devices, such as plastic boxes and heat-sealed plastic bags $[4,10,20]$, the gadgets we used worked equally well, but had advantages of safety to investigators and simple operation.

Overall, these tips enable experiments to be efficiently carried out but without using special equipment, so the costs of the experiment are greatly reduced, and the experiment can be easily performed and reproduced in a simple equipped molecular biology laboratory even by a novice investigator.

The best example of successful protocol modification: Eight rounds of rehybridization on a single blot

Table 1 summarizes the modifications made in this study and the resulting performance advantages of Northern blotting. As a whole, modifications made and tips used reported here not only improved detection sensitivity, but also enabled the efficient proceeding of Northern blotting, so the good performance of Northern blotting was achieved. Figure 1c shows the expression of photosynthetic-associated genes in leaves at the twoleaf stage of a chlorophyll-reduced mutant of oilseed rape detected in $20 \mu \mathrm{g}$ of total RNA using eight different probes. Full blots of these probes are provided in Suppl. Fig. 2, and the wash time to the desired counts and the exposure time for each probe are listed in Suppl. Table 1. Of the eight genes, GLO that encodes glycolate oxidase in peroxisome, is also a low expression gene in juvenile leaves [29]. To the best of our knowledge, eight rounds of rehybridization is currently the most reported reprobing time, which can also meet the requirements for the number of reprobing genes in most individual gene expression studies. The results of the current study indicated that the expressions of all eight genes investigated do not have significant difference in the leaves at the two-leaf stage of the mutant and its wildtype oilseed rape (Fig. 1c). Therefore, our successive research used the fully expanded cotyledon as materials because the differences in both gene expression and phenotype were quite obvious [30]. The distinct, sharp smear-free hybridization signal suggests that even if RNAs were extensively handled prior to blotting, RNA degradation did not occur; the clear hybridization signals were detected in all eight rounds of hybridization, indicating an efficient transfer of separated RNAs to the filter membrane and immobilization of the transferred RNAs on the solid support; good performance proved that our hybridization system using small gadgets was equivalently efficient. Compared with
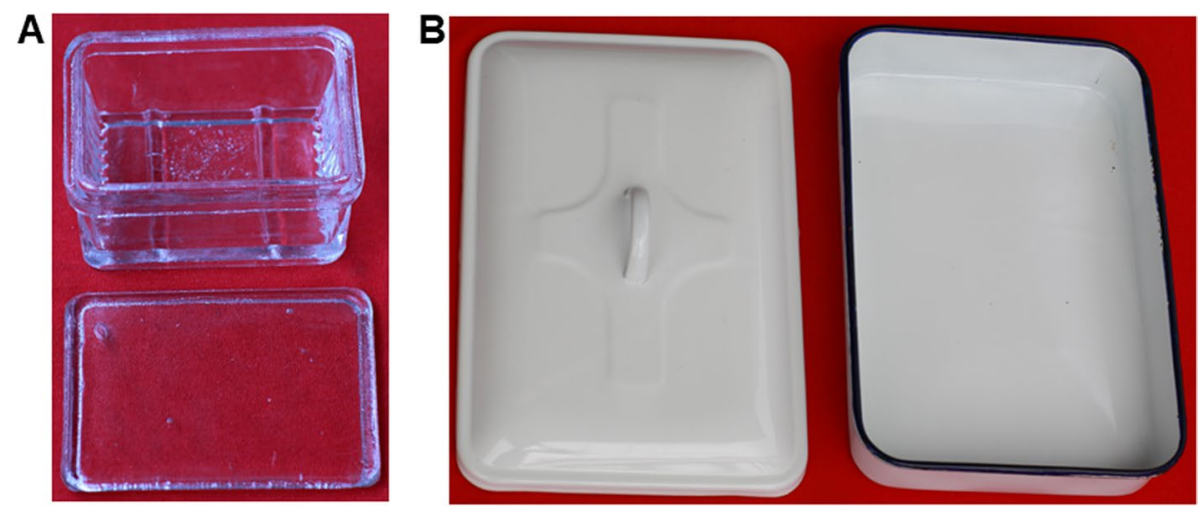

Fig. 3 Gadgets used for hybridization. a Staining jar. Normally, the staining jar is used for staining tissue slices, where the gadget was used for prehybridization and hybridization, and its bottom size is $7.2 \mathrm{~cm} \times 5.2 \mathrm{~cm}$, with the thickness of its wall being $0.5 \mathrm{~cm}$. The hybridization of the larger blotted membrane was performed in a glass Petri dish; $\mathbf{b}$ Enamel square tray with lid: During hybridization, the staining jar was placed into an enamel square tray, after being covered with the lid, the enamel tray was taken into a lab incubator to hybridize at $42{ }^{\circ} \mathrm{C}$. The thick glass of the staining jar, the metallic material and the enamel of the enamel square tray can protect investigators from hazardous radiation, and prevent the evaporation of toxic formamide and the spillage of radioactive materials 


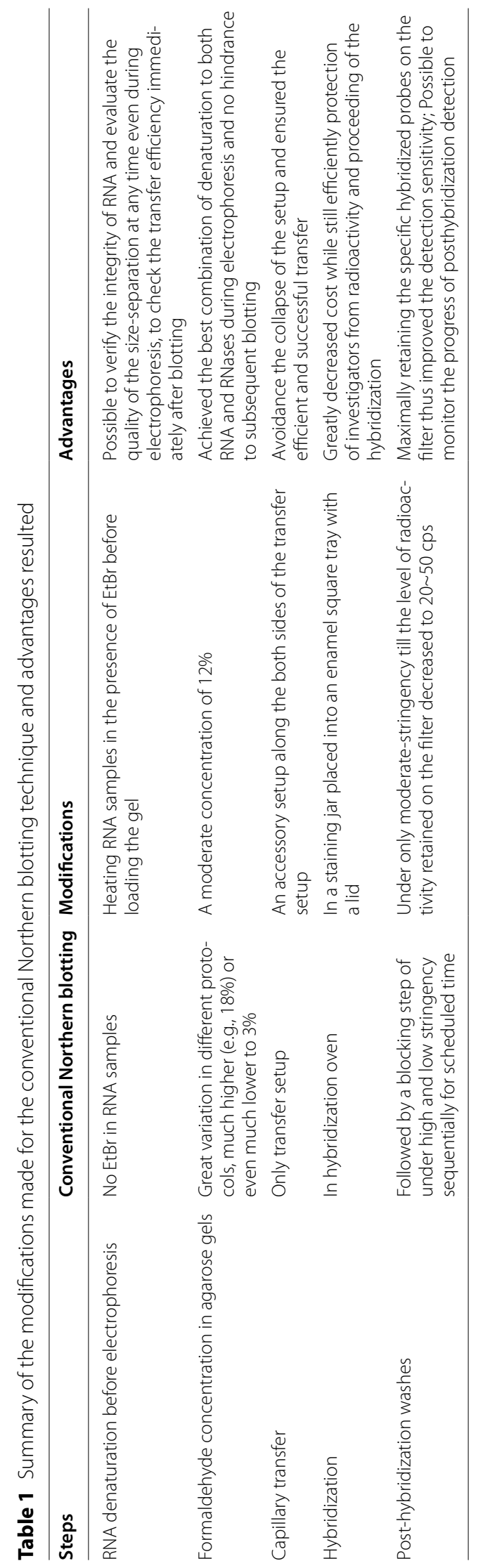


the newly reported improved Northern protocol [16], no special reagents or apparatus were used in our protocol, and thus the financial demands for the experiment were greatly reduced. Furthermore, our modifications enabled us to directly and easily check the proceeding of Northern blotting in the steps of electrophoresis, capillary transfer, and posthybridization detection. Therefore, the experiment can be monitored and evaluated step by step. Overall, the modified Northern protocol not only improved detection sensitivity, but also made the Northern blotting experiment easy, less expensive, reliable, and controllable.

\section{Conclusions}

Northern blot analysis has a unique advantage of providing information on expression level and native size of the RNA, and the direct quantitation of the signal also makes it a technique that provides highly valid expression data, so it is still a widely used technique as a gold standard for the direct study of gene expression at the RNA level and to detect transcript sizes $[4,9,13]$. However, the low detection sensitivity, high quality of RNA required, and the long time it takes to complete an analysis make it an undesirable method for analyzing RNA [1, 3, 4, 9]. Our aim was to optimize the traditional protocol by tweaking at the steps of electrophoresis, capillary transfer, hybridization, and posthybridization washes, so as to make the technique more applicable for standard use. Although the steps were not simplified and the time to complete was not saved, the modified Northern protocol improved the detection sensitivity and made the multi-step, laborintensive experiment easy, less expensive, reliable, and controllable. Therefore, this technique can be easily reproduced in a routine molecular biology laboratory and used to monitor low-abundance mRNA expression with heterologous DNA probes in total RNA, even when the cell or tissue source are limited and homologous DNA or RNA probes are not readily available.

\section{Methods \\ RNA isolation and size-separation through formaldehyde agarose gels}

Total RNA was isolated from vernalized shoots of Triticum aestivum at $0 \sim 2{ }^{\circ} \mathrm{C}$ for $0,10,20$, and $30 \mathrm{~d}$, respectively, or from leaves of the field-grown chlorophyll reduced mutant in Brassica napus [30] and its wild type at two-leaf stage, essentially according to the method of Zhang et al [31] and with modifications described in Zhang et al. [32]. The RNA was dissolved in diethylpyrocarbonate (DEPC)-water and an equal aliquot (20 or $50 \mu \mathrm{g}$ ) was heat-denatured at $65^{\circ} \mathrm{C}$ in the presence of $10 \mu \mathrm{g} / \mathrm{mL} \mathrm{EtBr}$ and resolved using the agarose gel containing $12 \%$ formaldehyde according to the method of Zhao et al. [18].

\section{Capillary transfers}

After electrophoresis, the gel was soaked in DEPC- $\mathrm{H}_{2} \mathrm{O}$ for $10 \mathrm{~min}$ with gentle shaking to remove formaldehyde, and then soaked in $50 \mathrm{mM} \mathrm{NaOH}$ for 20 min to partially hydrolyze the RNAs in the gel. After being soaked in 20 $\times \mathrm{SSC}(1 \times \mathrm{SSC}$ is $0.15 \mathrm{M} \mathrm{NaCl}, 0.015 \mathrm{M}$ sodium citrate, $\mathrm{pH} \mathrm{7.0)}$ for $45 \mathrm{~min}$, the partially-hydrolyzed RNAs were transferred to a positively charged nylon membrane (Boehringer Mannheim, Germany) using a conventional capillary method for $18 \mathrm{~h}$ as described in most protocols $[4,10,19,20]$. Our modification was to add an accessory setup by placing two supports on both sides of the transfer setup, and just ensuring that the height of the support was just lower than that of the paper towels, and then placing an elastic strip (using a long plastic ruler) across the glass plate and two supports. After pressing both ends of the strip, a $200 \mathrm{~g}$ weight was placed in the middle of the strip above the glass plate (Fig. 2). At the beginning of the transfer, when the first several layers of paper towels on the filter paper became wet, they were withdrawn and flattened with the pull of the hands, after which the extended edges were trimmed to match the gel size, the flattened paper towels were returned to the transfer setup, and then the transfer process was resumed. After blotting, the gel was directly placed on an UV transilluminator to check the transfer efficiency; the blotted membrane was briefly rinsed in $2 \times \mathrm{SSC}$, and then placed between two sheets of filter paper and allowed to air dry. After baking at $80{ }^{\circ} \mathrm{C}$ for $2 \mathrm{~h}$, the filter was directly subjected to the hybridization step or stored sandwiched between two sheets of filter paper, which was placed in a dry location out of light until further use.

\section{Prehybridization and hybridization}

The blotted membrane was prehybridized and hybridized with ${ }^{32} \mathrm{P}$-labeled probes at $42{ }^{\circ} \mathrm{C}$ according to Clark [20]. Prehybridization was performed in a glass staining jar, whose bottom size was $7.2 \mathrm{~cm} \times 5.2 \mathrm{~cm}$ and the thickness of the wall was $0.5 \mathrm{~cm}$ (Fig. 3a), which was with gentle shaken. After adding radioactively labeled probes to the prehybridization buffer, the staining jar was placed into an enamel square tray with a lid (Fig. 3b). After covering the lid, the enamel tray was taken into a laboratory incubator and stationary hybridization was allowed at $42{ }^{\circ} \mathrm{C}$ for $15 \mathrm{~h}$. The hybridization probes used for the detection of gene expression in vernalized wheat were the Aox 1 cDNA from Nicotiana tabacum [28] and a partial fragment of $18 \mathrm{~S}$ rDNA by amplification from $B$. napus, respectively. The hybridization probes used for detection of gene expression in B. napus were Aox 1 as 
described above, RbcS, Lhcb1, GLO, PsbA and Actin 1 as described in Zhang et al. [30], $16 \mathrm{~S}$ rDNA as described in Zhu et al. [33], and $R b c L$ as described in Wang et al. [34]. The information of all probes used in this study is listed in Suppl. Table 2. The probe fragments were labeled with $50 \mu \mathrm{Ci}$ of $\left[\alpha{ }^{-32} \mathrm{P}\right] \mathrm{dCTP}(380 \mathrm{MBq} / \mathrm{mL})$ by the random primer method using a Random Primer DNA Kit Ver 2.0 (TaKaRa Bio Inc., Dalian, China) according to the manufacturer's instructions. The labeled probes were used directly for hybridization without purification to remove unincorporated nucleotides. To obtain DNA probes with high specific activity, the length of the template DNA for labeling should be greater than $300 \mathrm{bp}$, and the amount should be lower approximately $25 \mathrm{ng}$. The specific activity of the labeled probes was $1 \sim 1.6 \times 10^{9} \mathrm{dpm} / \mu \mathrm{g}$.

\section{Posthybridization washes}

Posthybridization washes were performed under only moderately stringent conditions in $1 \times \mathrm{SSC} / 0.1 \% \mathrm{SDS}$ at $55^{\circ} \mathrm{C}$. A Geiger counter was used to monitor the level of radioactivity on the membrane until it was reduced to 20 to $50 \mathrm{cps}$. The wash solution was changed every $10 \mathrm{~min}$ whenever the level of the radioactivity on the membrane was too high. The membrane washed to the desired counts was placed between two sheets of filter paper to blot excessive buffer, and then wrapped in plastic wrap and exposed to an X-ray film with intensifying screens at $-80{ }^{\circ} \mathrm{C}$. Hybridization signals from the autoradiographs were quantified using the analysis tool of the SynGene bioimaging system. Posthybridization washes were also performed as the traditional protocol under low and high stringency sequentially for scheduled time (in $2 \times$ $\mathrm{SSC} / 0.5 \% \mathrm{SDS}$ at room temperature twice for $10 \mathrm{~min}$, and in $0.5 \times \mathrm{SSC} / 0.2 \% \mathrm{SDS}$ at $62{ }^{\circ} \mathrm{C}$ for $10 \mathrm{~min}$, respectively) according to Clark [20], or under only high stringency in $0.5 \times \mathrm{SSC} / 0.2 \% \mathrm{SDS}$ at $62{ }^{\circ} \mathrm{C}$ according to Borecký et al. [27].

\section{Stripping the probe}

After recording the image, the probe on the damp membrane was stripped in $0.1 \times \mathrm{SSC} / 0.1 \%$ SDS (preheated to $100{ }^{\circ} \mathrm{C}$ ), and then reprobed with another probe, as described by Zhao et al. [18]. The membrane could be immediately reused or stored as described above. It should be noted that the filter must not dry out, otherwise, the bound hybridized probe would be difficult to remove.

Theoretically, the blotted membrane can withstand rehybridization many times, but after each cycle of hybridization and probe stripping, a fraction of RNA immobilized on the membrane leaches away, so the signal strength decreases progressively with each use [4]. For this reason, the blotted membrane can only be stripped and rehybridized for limited times, and the reprobing was recommended to follow the order of expected low to high abundance signals.

\section{Abbreviations}

cps: Counts per second; DEPC: Diethylpyrocarbonate; EtBr: Ethidium bromide; PCR: Polymerase chain reaction; qPCR: Real-time PCR; RNase: Ribonuclease; RT: Reverse transcription; UV: Ultraviolet.

\section{Supplementary Information}

The online version contains supplementary material available at https://doi. org/10.1186/s12864-021-08275-w.

Additional file 1.

Acknowledgements

Thanks to Prof. Jim Whelan for generously providing us with the Aox 1 probe.

\section{Authors' contributions}

T.Y. and N. Z. designed the research; T. Y. and M. Z. performed the research; T. Y., M. Z. and N. Z. analyzed the data; N. Z. wrote the paper. The author(s) read and approved the final manuscript.

\section{Funding}

This work was supported by grants from the National Natural Science Foundation of China (No. 31071334), and the Scientific Research Foundation for the Returned Overseas Chinese Scholars of Ministry of Education (2011-1568).

Availability of data and materials

All data generated or analyzed during this study are included in this published article (and its supplementary information files).

\section{Declarations}

Ethics approval and consent to participate Not applicable.

Consent for publication

Not applicable.

\section{Competing interests}

The authors declare that they have no competing interests.

Received: 23 February 2021 Accepted: 22 December 2021 Published online: 20 January 2022

References

1. Bartlett JMS. Approaches to the analysis of gene expression using mRNA. Mol Biotechnol. 2002;21:149-60.

2. Hrdlickova R, Toloue M, Tian B. RNA-Seq methods for transcriptome analysis. Wiley Interdiscip Rev RNA. 2017;8. https://doi.org/10.1002/wrna.1364.

3. Dvořák Z, Pascussi JM, Modrianský M. Approaches to messenger RNA detection-comparison of methods. Biomed Pap. 2003;147:131-5.

4. Green MR, Sambrook J, Molecular Cloning. A laboratory manual. 4th ed. New York: Cold Spring Harbor Laboratory Press; 2012

5. Böhm-Hofstätter $\mathrm{H}$, Tschernutter M, Kunert R. Comparison of hybridization methods and real-time PCR: their value in animal cell line characterization. Appl Microbiol Biotechnol. 2010;87:419-25.

6. VanGuilder HD, Vrana KE, Freeman WM. Twenty-five years of quantitative PCR for gene expression analysis. Biotechniques. 2008;44:619-26.

7. Bustin SA. Why the need for qPCR publication guidelines? The case for MIQE. Methods. 2010:50:217-26. 
8. Lanoix D, Lacasse A-A, St-Pierre J, Taylor SC, Ethier-Chiasson M, Lafond J, Vaillancourt C. Quantitative PCR pitfalls: the case of the human placenta. Mol Biotechnol. 2012;52:234-43.

9. Streit S, Michalski CW, Erkan M, Kleeff J, Friess H. Northern blot analysis for detection and quantification of RNA in pancreatic cancer cells and tissues. Nat Protoc. 2009;4:37-43.

10. Farrel RE Jr. RNA methodologies: a laboratory guide for isolation and characterization. 4th ed. San Diego: Elsevier, Academic Press; 2010.

11. Bhardwaj AR, Pandey R, Agarwal M, Katiyar-Agarwal S. Northern blotting technique for detection and expression analysis of mRNAs and small RNAs. Methods Mol Biol. 2021;2170:155-83.

12. Wiegard JC, Schlüter MAC, Burenina OY, Kubareva EA, Klug G, Grünweller A, Hartmann RK. Northern blot detection of tiny RNAs. Methods Mol Biol. 2021;2300:41-58.

13. Schlamp K, Weinmann A, Krupp M, Maass T, Galle PR, Teufel A. BlotBase: a northern blot database. Gene. 2008;427:47-50

14. Krüßel L, Ostendorp S, Ostendorp A, Kehr J. Detection of RNA in ribonucleoprotein complexes by blue native Northern blotting. Methods $\mathrm{Mol}$ Biol. 2021;2170:45-51.

15. Mishima E, Abe T. Immuno-Northern blotting: detection of modified RNA using gel separation and antibodies to modified nucleosides. Methods Mol Biol. 2019;1870:179-87.

16. Ahmad W, Gull B, Baby J, Mustafa F. A comprehensive analysis of Northern versus liquid hybridization assays for mRNAs, small RNAs, and miRNAs using a non-radiolabeled approach. Curr Issues Mol Biol. 2021;43:457-84.

17. Miller BR, Wei T, Fields CJ, Sheng P, Xie M. Near-infrared fluorescent northern blot. RNA. 2018;24:1871-7.

18. Zhao Y, Du LF, Zhang NH. Sensitivity of prestaining RNA with ethidium bromide before electrophoresis and performance of subsequent Northern blots using heterologous DNA probes. Mol Biotechnol. 2013:54:204-10

19. Brown T, Mackey K, Du TT. Analysis of RNA by Northern and slot blot hybridization. Protoc Mol Biol. 2004;67:4.9.1-4.9.19.

20. Clark MJ. Plant molecular biology: a laboratory manual. Berlin Heidelberg: Springer-Verlag; 1997.

21. Suleman M, Ma M, Ge G, Hua D, Li H. The role of alternative oxidase in plant hypersensitive response. Plant Biol (Stuttg). 2021;23:415-9.

22. Vanlerberghe GC, McIntosh L. Mitochondrial electron transport regulation of nuclear gene expression. Plant Physiol. 1994;105:867-74.

23. Vanlerberghe GC, Mclntosh L. Signals regulating the expression of the nuclear gene encoding alternative oxidase of plant mitochondria. Plant Physiol. 1996;111:589-95.

24. Abe F, Saito K, Miura K, Toriyama K. A single nucleotide polymorphism in the alternative oxidase gene among rice varieties differing in low temperature tolerance. FEBS Lett. 2002;527:181-5.

25. McCabe TC, Finnegan PM, Millar AH, Day DA, Whelan J. Differential expression of alternative oxidase genes in soybean cotyledons during postgerminative development. Plant Physiol. 1998;118:675-82.

26. Takumi S, Tomioka M, Eto K, Naydenov N, Nakamura C. Characterization of two non-homoeologous nuclear genes encoding mitochondrial alternative oxidase in common wheat. Genes Genet Syst. 2002;77:81-8.

27. Borecký J, Nogueira FTS, de Oliveira KAP, Maia IG, Vercesi AE, Arruda P. The plant energy-dissipating mitochondrial systems: depicting the genomic structure and the expression profiles of the gene families of uncoupling protein and alternative oxidase in monocots and dicots. J Exp Bot. 2006;57:849-64.

28. Whelan J, Smith MK, Meijer M, Yu JW, Badger MR, Price CD, Day DA. Cloning of an additional CDNA for the alternative oxidase in tobacco. Plant Physiol. 1995;107:1469-70.

29. Timm S. The impact of photorespiration on plant primary metabolism through metabolic and redox regulation. Biochem Soc Trans. 2020:48:2495-504.

30. Zhang NH, Zhao Y, Liang HG, Sun JY, Du LF. A new gun mutant of oilseed rape with reduced porphyrin flux through Mg-chelatase. Acta Physiol Plant. 2013;35:75-84.

31. Zhang NH, Wei ZQ, He JX, Du LF, Liang HG. An efficient and economic method for preparation of high quality plant RNA. Prog Biochem Biophys. 2004;31:947-50.

32. Zhang NH, Yu D, Zhu XF. RNA isolation from plant tissues: a hands-on laboratory experimental experience for undergraduates. Biochem Mol Biol Edu. 2018;46:253-61.
33. Zhu YS, Kung SD, Bogorad L. Phytochrome control of levels of mRNA complementary to plastid and nuclear genes of maize. Plant Physiol. 1985;79:372-6

34. Wang T, Zhang NH, Du LF. Isolation of RNA of high quality and yield from Ginkgo biloba leaves. Biotechnol Lett. 2005;27:629-33.

\section{Publisher's Note}

Springer Nature remains neutral with regard to jurisdictional claims in published maps and institutional affiliations.
Ready to submit your research? Choose BMC and benefit from:

- fast, convenient online submission

- thorough peer review by experienced researchers in your field

- rapid publication on acceptance

- support for research data, including large and complex data types

- gold Open Access which fosters wider collaboration and increased citations

- maximum visibility for your research: over $100 \mathrm{M}$ website views per year

At BMC, research is always in progress.

Learn more biomedcentral.com/submissions 